\title{
Predicting the occurrence of sand banks in the North Sea
}

\author{
H. Henriët van der Veen • Suzanne M. J. H. Hulscher
}

Received: 27 November 2008 / Accepted: 12 May 2009/Published online: 30 May 2009

(C) The Author(s) 2009. This article is published with open access at Springerlink.com

\begin{abstract}
Sand banks have a wavelength between 1 and $10 \mathrm{~km}$, and they are up to several tens of meters high. Also, sand banks may have an impact on large-scale human activities that take place in the North Sea like sand mining, shipping, offshore wind farms, etc. Therefore, it is important to know where sand banks occur and what their natural behavior is. Here, we use an idealized model to predict the occurrence of sand banks in the North Sea. The aim of the paper is to research to what extent the model is able to predict the occurrence of sand banks in the North Sea. We apply a sensitivity analysis to optimize the model results for a North Sea environment. The results show that the model correctly predicts whether or not sand banks occur for two thirds of the North Sea area.
\end{abstract}

Keywords Sand banks $\cdot$ North Sea $\cdot$ Idealized model

\section{Introduction}

Shelf seas like the North Sea are areas that are biologically highly active and provide most of the world's main fisheries. Often, the seabed contains high concentrations of oil and gas supplies and most shelf seas are very busy shipping areas. In most shelf seas, sediment is widely abundant, and due to the fact that in these areas the largest part of the tidal and wave energy is dissipated, the bed is

Responsible Editor: Alejandro J. Souza

H. H. van der Veen $(\varangle) \cdot$ S. M. J. H. Hulscher

Water Engineering and Management, University of Twente, P.O. Box 217, 7500AE Enschede, The Netherlands

e-mail: h.h.vanderveen@utwente.nl

S. M. J. H. Hulscher

e-mail: s.j.m.h.hulscher@utwente.nl shaped in a range of bed forms by the tidal flow over the erodible bed (Brown et al. 1999). The smallest of these forms are ripples with a height in the order of centimeters and somewhat larger are megaripples. Also, sand waves occur on the seabed, and they have a wavelength in the order of hundreds of meters and can be several tens of meters high. Here, we focus on the largest offshore bed forms: sand banks. An overview of sand bank occurrence in the North Sea is given in Fig. 1.

Sand banks can either be formed by tide-seabed interactions or they are relict features in the current tidal regime. Banks that are formed by the tide can be either actively maintained or moribund. Actively maintained sand banks were formed by the modern tidal regime. Moribund sand banks were formed during periods of lower sea levels, and they occur in deeper water where the present tidal current is too weak to form sand banks (no sediment transport occurs under the present tidal current) (Collins et al. 1995). Moribund banks are not covered with sand waves and have more rounded crests than active sand banks. Also, their slopes are gentler, in the order of $1^{\circ}$. These banks are mostly separated by a sandy or muddy seafloor. Relict sandbanks were not formed by (present or former) flowtopography interaction. However, they can be intensively reworked by the present regime. Banks often store large amounts of sand and they appear to be hydraulically maintained. The most common situations that lead to accumulation of sediment are a reversal in the sand transport direction involving bedload convergence or a reduction in shear stress (Dyer and Huntley 1999).

The North Sea is a shallow shelf sea. The tides in the southern part are semi-diurnal and the tidal amplitudes ranges from $2.4 \mathrm{~m}$ in the Strait of Dover to $0.6 \mathrm{~m}$ more to the North (Davies et al. 1997). At spring tide, the flow velocities at the surface vary from $1.4 \mathrm{~m} / \mathrm{s}$ in the western 


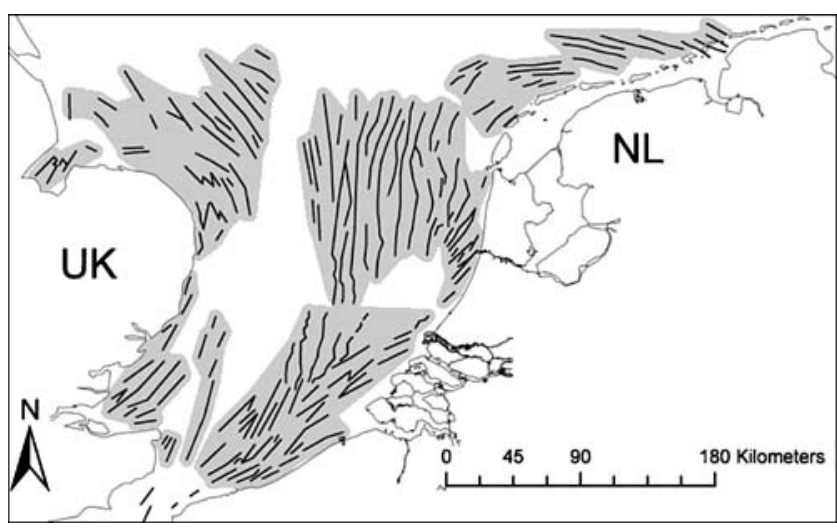

Fig. 1 An overview of the southern part of the North Sea. The black lines denote sand bank occurrence adapted after Dyer and Huntley (1999). The gray areas denote the digitized areas that we used to compare to the model results

and southern part to $0.7 \mathrm{~m} / \mathrm{s}$ along the Dutch coast and the northern part (Hydrographical_Survey 2000). The seabed consists mainly of fine to medium sands, ranging from 125 to $500 \mu \mathrm{m}$, but at some places, in the Strait of Dover and in front of the coast of East Anglia (UK), patches of gravel have been observed (Jarke 1956).

Bed forms can interact with human activities, as the North Sea is intensively used for various purposes. User functions that are affected by the large-scale morphology are navigation, telecommunication cables, oil and gas transportation (pipelines), oil and gas mining, sand extraction, artificial islands, and offshore wind farms. For safety reasons, it is important to know where the bed forms occur or might be generated and which parameters are crucial herein. The model underlying the prediction of sand waves, i.e., Hulscher (1996), is also capable to predict sand banks. In Van der Veen et al. (2006) we successfully predicted the occurrence of sand waves in the North Sea. In this paper, we investigate if the same model can be used to predict the occurrence of sand banks in the North Sea. The research question that we want to answer is: to what extent is the model able to predict the occurrence of sand banks in the North Sea?

Compared to Hulscher and Van den Brink (2001), who were the first to predict the occurrence of large-scale bed features in the North Sea, the model is improved by including a critical bed shear stress depending on the grain size. This means that a certain threshold has to be exceeded before sediment transport and therefore evolution of sand banks takes place. Also, Hulscher and Van den Brink (2001) did not compare the model prediction for sand banks with observations of sand bank occurrence, and therefore, the model results were not validated for the prediction of sand banks. This paper focuses exclusively on the sand bank predictions made by the model and compares these with observations of sand banks.
This paper is organized as follows: in Section 2, the idealized model (Hulscher 1996) is described. In Section 3, model results are listed and we compare these results with observations of sand banks. We also investigate the sensitivity of two model parameters, which determine the turbulence model, namely the viscosity variation parameter $(\varepsilon)$ and the level of zero intercept $\left(z_{0}\right)$. Section 4 contains the discussion, and in Section 5, the conclusions are listed.

\section{Model}

\subsection{The model to predict large-scale bed forms}

The three-dimensional model of Hulscher (1996) explains how tidal currents form rhythmic bed patterns in sandy beds. The model is based on the threedimensional shallow water equations, applied to a tidal flow. An empirical bed load transport, which includes slope effects, models the sediment transport and the bed level changes are calculated using a sediment balance. In Hulscher (1996), tide and seabed are regarded as a coupled system. The bed patterns are assumed to be free instabilities of this system, and similar model approaches have been applied earlier by, e.g., Prandle (1982). A linear stability analysis is performed to study pattern dynamics, which means that only small amplitude perturbations are considered. The model calculates growth rates for every wavelength and orientation which characterize the spatial structure of the pattern. If all growth rates are negative, all bed patterns are damped and so the flat bed is stable. In this research, we define a flat bed as a bed where no large-scale bed forms occur. However, if at least one bed pattern has a positive growth rate, the flat bed is unstable and a wavy bed pattern develops. For a more elaborate description of the model, see Hulscher (1996). This paper focuses on the generation of tidal sand banks: it does not deal with the geomorphic properties (spacing, migration) of tidal sand banks, and we use the model to predict the occurrence of tidal sand banks in the North Sea. In the case of a moderate resistance (small resistance parameter $(\hat{S})$ and large Stokes number $\left.\left(E_{\mathrm{v}}\right)\right)$, the Stokes boundary layer is much thicker than the water depth and the vertical shear in the horizontal velocities is small. Then, the flow resembles the depth-averaged $(2 \mathrm{DH})$ flow in the sand bank model of Hulscher et al. (1993).

The values of the resistance parameter $(\hat{S})$ and the Stokes number $\left(E_{\mathrm{v}}\right)$ are estimated by fitting the partial slip model used in Hulscher (1996) to a more realistic turbulence model including the no-slip condition at the bed and a parabolic eddy viscosity distribution (Hulscher 
and Van den Brink 2001), which leads to the following expressions:

$E_{\mathrm{v}}=\frac{3 \pi u}{4 H \sigma} \frac{\kappa^{2} B}{A}$

$\widehat{S}=\frac{3 \pi u}{4 H \sigma} \frac{\kappa^{2} B}{A(A B-1 / 3)}$

Where:

$A=\left[\ln \left(\frac{H}{z_{0}}\right)-\frac{1}{\varepsilon}+\frac{1-\varepsilon}{\varepsilon} \ln \left(\frac{1-\varepsilon}{1-\varepsilon \frac{z_{0}}{H}}\right)+\frac{\varepsilon-1}{\varepsilon^{2}} \ln (1-\varepsilon)\right]$

$B=\frac{3-2 \varepsilon}{6}$

In which, $\kappa(0.41)$ is the von Kármán constant, $u$ is the depth-averaged flow velocity, $H$ is the local mean water depth, $\sigma$ is the tidal frequency, and $\varepsilon$ is the viscosity variation parameter (which denotes the influence of waves), which may vary between 0 and 1 , where $\varepsilon=1$ represents a parabolic distribution over the water column and no influence of waves, and $\varepsilon=0$ represents a linear increase of the eddy viscosity (Soulsby 1990) and resembles the situation in which there is influence of waves and wind on the eddy viscosity, which is denoted by (Hulscher and Roelvink 1997):

$v=\kappa \widehat{u}_{*} z\left(1-\varepsilon \frac{z}{H}\right)$

In which $z$ denotes the position above the bed and $\hat{u}_{*}$ is the friction velocity, see also Fig. 2.

The parameter $z_{0}$ denotes the level of zero-intercept (the level above the seabed, where the flow velocity is zero).
The value of $z_{0}$ varies with grain size and can also be influenced by the occurrence of bed forms like ripples and megaripples. To predict the occurrence of sand banks in the North Sea, we used values of $z_{0}$ based on the characteristics of megaripples in the North Sea (Tobias 1989). This is analogous to Hulscher and Van den Brink (2001) and references herein and is defined by (Soulsby 1983):

$z_{0}=2 \Delta_{\mathrm{r}}\left(\frac{\Delta_{\mathrm{r}}}{\lambda_{\mathrm{r}}}\right)^{1.4}$

In which $\Delta_{\mathrm{r}}=\alpha_{\mathrm{mr}} H$ and $\lambda_{\mathrm{r}}=\beta_{\mathrm{mr}} H$ after Van Rijn (1993), where $\alpha_{\mathrm{mr}}(0.03)$ and $\beta_{\mathrm{mr}}(0.5)$ are dimensionless coefficients for the megaripple regime in the North Sea (Tobias 1989).

A grain size dependency is included in the model. The grain size of the sediment influences the initiation of motion of the grains. Sediment transport takes place if the bed shear stress $\left(\tau_{\mathrm{b}}\right)$ exceeds the critical shear stress $\left(\tau_{\mathrm{cr}}\right)$.

The critical bed shear stress $\tau_{\text {cr }}$ is denoted by:

$\tau_{\mathrm{cr}}=\theta_{\mathrm{cr}} g\left(\rho_{\mathrm{s}}-\rho\right) d_{50}$

Where $g$ is the gravitational acceleration $\left(9.81\left(\mathrm{~m} / \mathrm{s}^{2}\right)\right), \rho$ is the density of seawater $\left(1,025 \mathrm{~kg} / \mathrm{m}^{3}\right), \rho_{\mathrm{s}}$ is the sediment density $\left(2,650 \mathrm{~kg} / \mathrm{m}^{3}\right), d_{50}$ is the median grain size, and $\theta_{\mathrm{cr}}$ is the critical Shields parameter which is calculated using the equation of Soulsby and Whitehouse (1997):

$\theta_{\mathrm{cr}}=\frac{0.30}{1+1.2 D_{*}}+0.055\left[1-\exp \left(-0.020 D_{*}\right)\right]$

In which $D_{*}$ is the dimensionless sediment parameter, denoted by:

$D_{*}=d_{50}\left[\frac{s g}{v^{2}}\right]^{\frac{1}{3}}$

Where $s$ is the relative density and $v$ is the kinematic viscosity of water $\left(1.36 \times 10^{-6}\left(\mathrm{~m}^{2} / \mathrm{s}\right)\left(\right.\right.$ at $\left.\left.10^{\circ} \mathrm{C}\right)\right)$.
Fig. 2 Eddy viscosity $(\nu)$ as function of the water depth for different values of the viscosity variation parameter $\varepsilon$
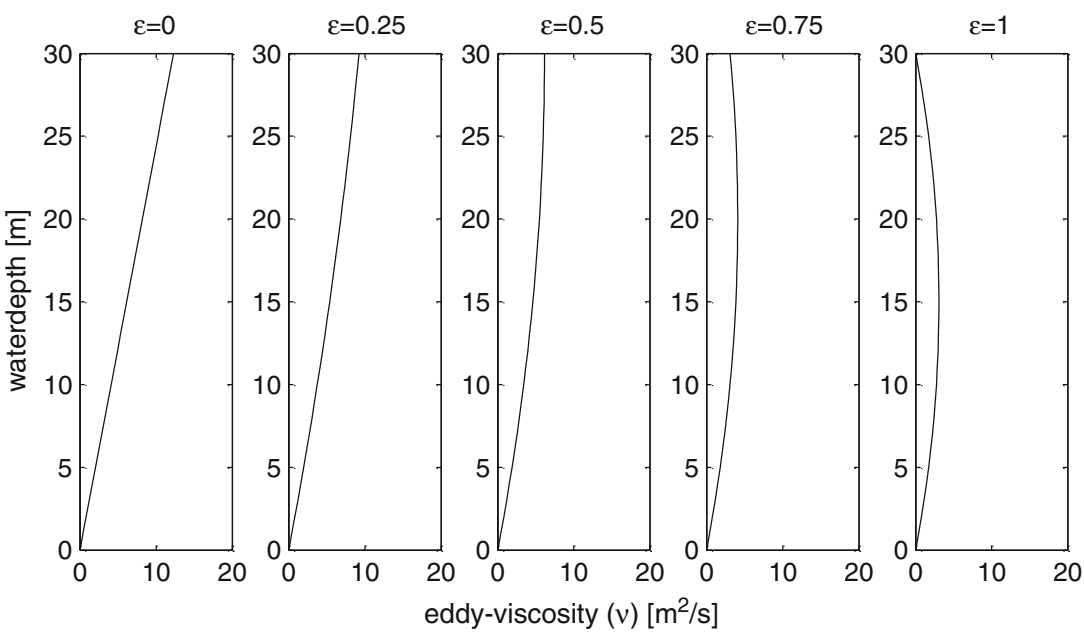
The bed shear stress is denoted by:

$\tau_{\mathrm{b}}=\rho C_{\mathrm{D}} u^{2}$

In which $u$ is the depth-averaged flow velocity and $C_{D}$ is defined by (Soulsby 1997):

$C_{\mathrm{D}}=0.0415\left(\frac{z_{0 \text { skin }}}{H}\right)^{\frac{2}{7}}$

In which $z_{0 \text { skin }}$ is the level of zero intercept due to grain size only:

$z_{0 \text { skin }}=\frac{d_{50}}{12}$

The bed shear stress $\tau_{\mathrm{b}}$ and the critical bed shear stress $\tau_{\mathrm{cr}}$ are calculated using the site-specific parameters (grain size, water depth, and flow velocity) as input parameters. In the model, we assume that sediment transport only takes place if the bed shear stress exceeds the critical bed shear stress:

$$
\begin{array}{llll}
\tau_{\mathrm{b}} \leq \tau_{\mathrm{cr}} & \rightarrow & \vec{S}_{\mathrm{b}}=0 \\
\tau_{\mathrm{b}}>\tau_{\mathrm{cr}} & \rightarrow & \vec{S}_{\mathrm{b}}=\alpha\left|\vec{\tau}_{\mathrm{b}}\right|^{b}\left\{\frac{\vec{\tau}_{\mathrm{b}}}{\left|\vec{\tau}_{\mathrm{b}}\right|}-\lambda \vec{\nabla} h\right\}
\end{array}
$$

We use a general sediment transport equation and only take into account bed load, which is assumed to be dominant in offshore tidal regimes (Hulscher 1996). Parameter $b$ $(\sim 1.5)$ denotes the non-linearity of transport in relation with the bed shear stress, $\lambda(\sim 2)$ is a bed-slope correction term, $h$ denotes the height of the bed form and $\alpha$ is a bed load transport proportionality parameter (Hulscher 1996).

\subsection{Data}

The data on the velocity of the M2 tidal component are interpolated from a grid of points provided by the RIKZ (Rijksinstituut voor Kust en Zee, now Deltares) and is derived from runs of the ZUNOWAK model (Van Dijk and Plieger 1988).

The water depth $(H)$ data were taken from Hulscher and van den Brink (2001) and originated from Boon and Gerritsen (1997) and Ten Brummelhuis (1997). The median grain size $\left(d_{50}\right)$ distribution of the southern North Sea was taken from different geographical maps (Rijks_Geologische Dienst 1984; Hydrographer_of the Navy 1992). Additional data on $d_{50}$ for the Dutch part of the North Sea were provided by TNO-NITG (now Deltares).

The data on sand bank occurrence are adapted from Dyer and Huntley (1999). The data of Dyer and Huntley only show the sand bank crests, and to get coverage of the whole sand bank area, a corridor of $5 \mathrm{~km}$ around the original areas is selected, which is assumed to be on average half the wavelength of a sand bank. Where the different areas overlap each other, they are merged, thus arriving at the sand bank occurrence in the southern part of the North Sea as is depicted in Fig. 1.

\subsection{Model runs}

First, we run the model for the southern part of the North Sea. We use the default value for $\varepsilon(0.5)$ and $z_{0}$ is defined by Eq. 6.

Second, we carry out a sensitivity analysis. Two input parameters, namely, the viscosity variation parameter $(\varepsilon)$ and the level of zero intercept $\left(z_{0}\right)$, have a large range of possible values. These parameters have been selected because they have a direct influence on the Stokes number and resistance parameter. Also, uncertainty about the value of these two parameters exists because they are influenced by environmental factors (such as waves, etc.). We carry out a sensitivity analysis to determine which values of these parameters lead to an optimal prediction of sand banks in the North Sea. This sensitivity analysis is included to optimize the model results with the observations of sand banks. The variation of these parameters does not directly influence the linear stability analysis but influences the model calculations through the resistance parameter $(S)$ (Eq. 2) and the Stokes number $\left(E_{\mathrm{v}}\right)$ (Eq. 1), thus varying these parameters leads to a different wave length calculated by the model. To investigate the sensitivity of the model for the level of zero intercept, we performed two tests. First, we use an overall fixed value for the level of zero intercept. We vary $z_{0}$ between $10^{-5}$ and $10^{-1} \mathrm{~m}$ to determine the effect on the prediction of sand banks. Second, we use the original locally determined varying level of zero intercept, i.e., based on the characteristics of megaripples, but we multiply the local values with a percentage ranging from $5 \%$ to $500 \%$ to see how this affects the predictions that are made by the model. This can also be understood as changes in the dimensionless parameters $\alpha_{\mathrm{mr}}$ and $\beta_{\mathrm{mr}}$ in the roughness predictor in Eq. 6, more specifically we varied the product: $\alpha_{\mathrm{mr}}^{2.4} \beta_{\mathrm{mr}}^{-1.4}$.

\section{Results}

\subsection{Model results}

Figure 3 shows the prediction (with default values $\varepsilon=0.5$ and $z_{0}$ defined by Eq. 6), of sand bank occurrence in the North Sea.

As can be seen in Fig. 3, the occurrence of sand banks is predicted in a large part of the southern North Sea. In a small area in the middle of the southern North Sea, between the British coast and the Dutch coast, sand banks are predicted exclusively. In the northern part of the North Sea, 


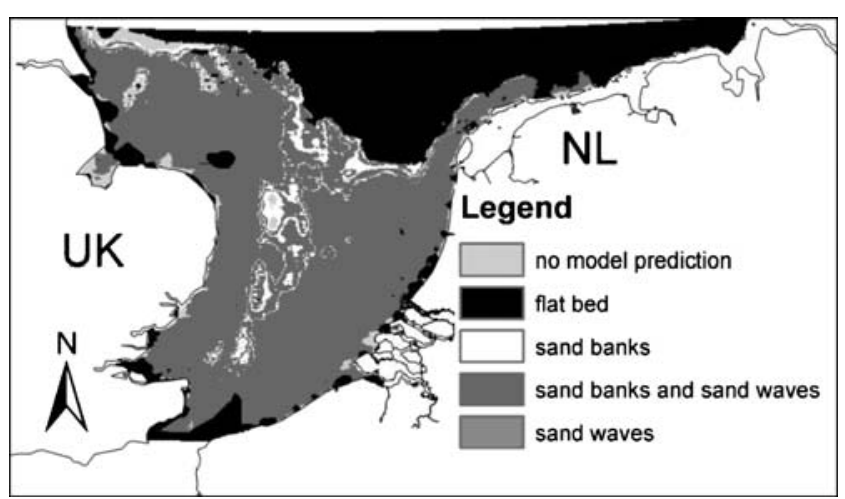

Fig. 3 Model prediction of sand banks in the North Sea

a flat bed is predicted. Note that also sand waves are predicted by the model, but here we only focus on the prediction of sand banks and do not discuss the prediction of sand waves.

3.2 Comparison of model results with observations of sand banks

Figure 4 shows the comparison between the model results and observations of sand banks.

The categories "predicted and observed" and "not predicted and not observed" represent the cases for which the model gives a correct prediction.

As can be seen, there is an over-prediction in the occurrence of sand banks (predicted but not observed). Also, the sand bank area in the northern part of the North Sea, off the coast of the Dutch Wadden Isles is not predicted correctly by the model. Quantitatively, the model gives a correct prediction in $64.5 \%$ of the area and an incorrect prediction in $32.5 \%$ of the area (in $3 \%$ of the area, the model does not give a prediction).

3.3 Sensitivity analysis of the viscosity variation parameter and the level of zero intercept

\subsubsection{Viscosity variation parameter $(\varepsilon)$}

We compared the model results for different values of $\varepsilon$ with observations of sand banks, and the results are plotted in Fig. 5.

The results in Fig. 5 show that the influence of $\varepsilon$ is rather limited. If the value of $\varepsilon$ is small ( 0.1$)$, the model predominantly predicts the occurrence of sand banks and gives a correct prediction in $60.1 \%$ of the area. If the value of $\varepsilon$ is increased (0.5), the prediction shifts to sand banks and sand waves; in this case, a correct prediction is given in $64.5 \%$ of the area. For large values of $\varepsilon(0.9)$, the model predicts the occurrence of exclusive sand waves for some areas in the southern North Sea, where a correct prediction is given in $62.3 \%$ of the area.

For smaller values of $\varepsilon(0.1)$, the area in which the model is unable to give a prediction increases to $7.6 \%$; when $\varepsilon$ is 0.5 , this is $3.0 \%$, and when $\varepsilon$ is 0.9 , this area is $5.2 \%$.

\subsubsection{Level of zero intercept $\left(z_{0}\right)$}

Figure 6 shows the sensitivity of the model to the overall fixed value of the parameter $z_{0}$. As can be seen, there is an optimum in the model prediction at a value of $z_{0}$ of about $1 \times 10^{-2} \mathrm{~m}$. If the value of $z_{0}$ increases, the percentage of correct prediction goes down but also, the percentage of area for which the model does not give a prediction increases sharply, thereby diminishing the applicability of the model. The locally determined variable values of $z_{0}$ that we used in the preceding section to predict the occurrence of sand banks, ranging between $2.3 \times 10^{-2}$ and $6.4 \times 10^{-2} \mathrm{~m}$.

Next, we test the variations in the parameters that determine the local roughness $z_{0}$ (Eq. 6), i.e., the product $\alpha_{\mathrm{mr}}^{2.4} \beta_{\mathrm{mr}}^{-1.4}$ ranging from $5 \%$ to $500 \%$.

As can be seen from Fig. 7, the optimum prediction is made for values of $z_{0}$ slightly smaller than the original values of $z_{0}$ (i.e., $100 \%$, which vary between $2.3 \times 10^{-2}$ and $6.4 \times 10^{-2} \mathrm{~m}$ ) that are used in the model to predict the occurrence of sand banks in the North Sea (Fig. 3). With the values used to predict the occurrence of sand banks in the North Sea in Section 3.1, we obtain a correct prediction for the occurrence of sand banks in $64.5 \%$ of the area. The maximum is reached if we use values that are slightly smaller $(80 \%)$. In this case, a correct prediction is given for $64.8 \%$ of the area, but the difference is very small.

\section{Discussion}

In general, the model predictions agree with the observations of sand banks that occur on the North Sea seabed.

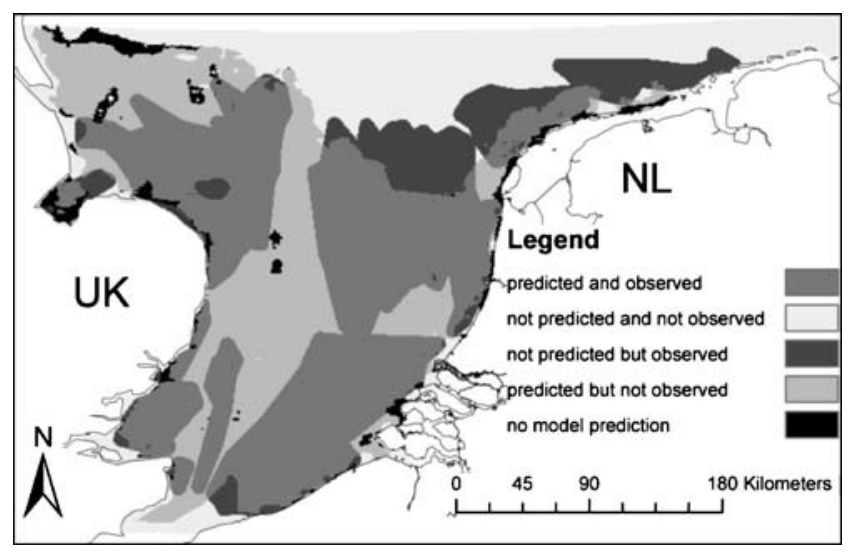

Fig. 4 Comparison of model predictions with observations of sand banks 

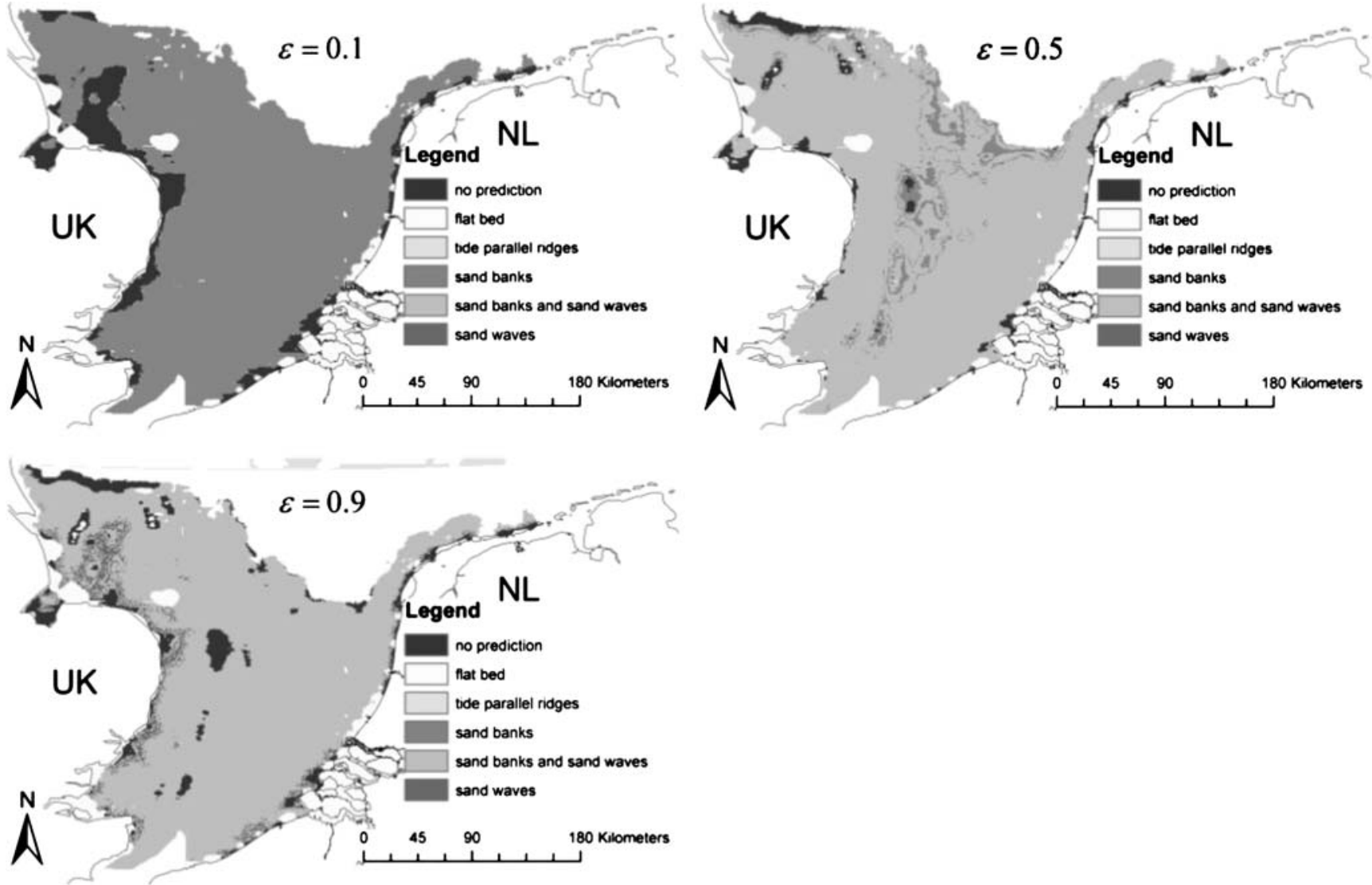

Fig. 5 Large-scale bed form predictions for different values of $\varepsilon(\varepsilon=0.1, \varepsilon=0.5, \varepsilon=0.9)$

However, there is an overprediction of the occurrence of sand banks.

In this paper, we also carried out a sensitivity analysis of the parameters that influence the effects of turbulence, as this determines whether sand banks (2DH) or sand waves (2DV circulations) are predicted. Different values of the

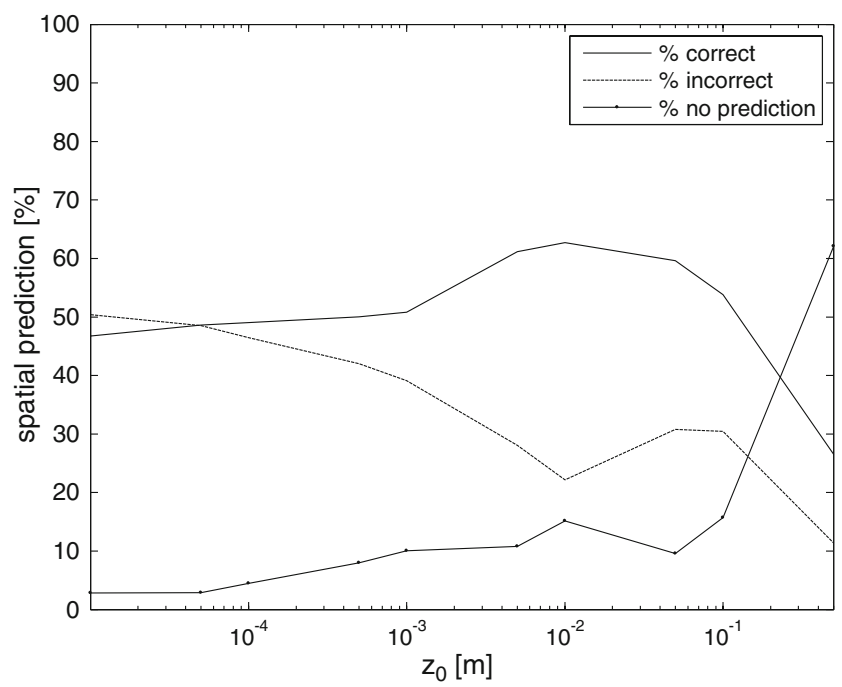

Fig. 6 Model prediction for different fixed values of level of intercept $\left(z_{0}\right)$ parameter $\varepsilon$ show a different eddy viscosity profile over the water depth. This variation is among others due to surface waves. We assume that large parts of the southern North Sea are sufficiently deep that the influence of wind waves does not reach the seabed. Wind waves may have an effect on the shallow parts of the North Sea, and in these areas,

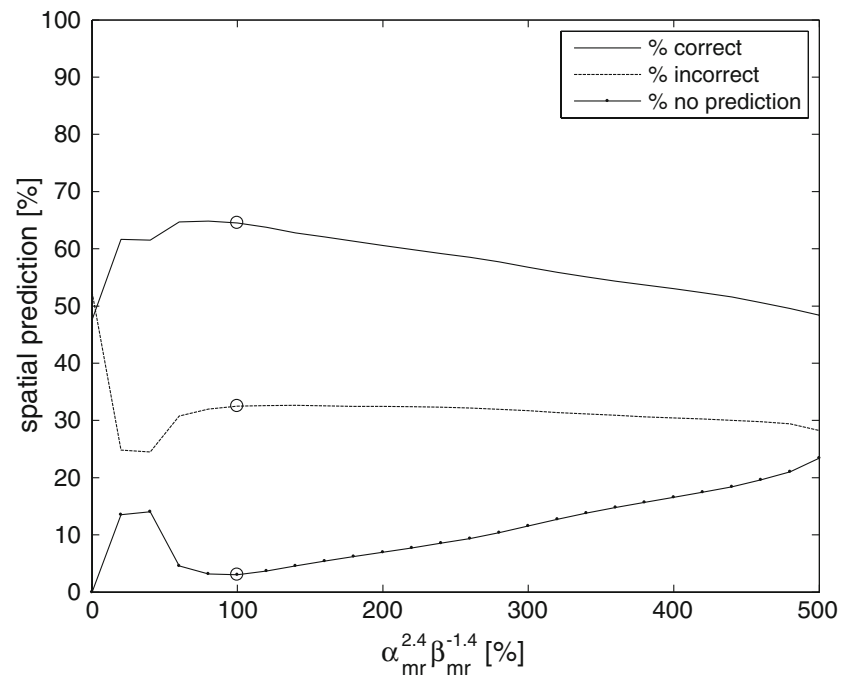

Fig. 7 Percentage of the varying $z_{0}$ (Eq. 6) ranging from $5 \%$ to $500 \%$. The circles denote the default situation as used in Section 3.1 
the resulting sediment transport may be larger than currently calculated by the model. Also, during storms, larger parts of the North Sea may be affected by wind waves; however, these situations occur only during brief periods of time and are therefore not included in the model. However, this influences the growth speed of the occurring bed feature but not the wavelength.

In the model, currently, only a critical shear stress is included. If this critical stress $\left(\tau_{\mathrm{cr}}\right)$ is exceeded, the sediment transport is calculated taking into account only the bed shear stress $\left(\tau_{\mathrm{b}}\right.$; and not the bed shear stress minus the critical shear stress). This means that the actually occurring sediment transport can be lower than calculated. In the model, however, this has no influence on the type of bed form that is predicted but only at the speed of the growth of the bed form. Since, here we look only at the equilibrium bed form that occurs, this has no influence on the bed-type prediction.

There could be other factors that influence the sand bank prediction that are not taken into account at the moment. Idier et al. (2007) state other factors that are influenced by a grain size dependency, like the friction coefficient, the sedimentary coefficient or bed slope proportionality parameter, and the bed slope coefficient in the sediment transport. For further research, it could be worthwhile to investigate the influence of these parameters on the prediction of sand bank occurrence in the North Sea.

The flow velocities from the Zunowak model are used solely as an input parameter in the GIS and no feedback to the Zunowak model occurs. The model of Hulscher (1996) starts from a flat bed and thus no seabed height variations are present. As the Zunowak model includes the topography of the North Sea seabed, one can argue that this is not a correct input for the model. However, we assume that the Zunowak grid that is used is sufficiently coarse that local variations due to the presence of sand banks do not show up in the data.

According to Van der Molen (2002), the tides in the Southern bight of the North Sea are semi-diurnal with dominant M2 tides along the coast. A larger flow velocity in the model would lead to a faster evolution of the sand banks but does not influence the wave type of the developing bed feature. Roos et al. (2004) state that the inclusion of an M4 and/or an M6 overtide with a phase difference leads to migration, asymmetry, or a reduction of height of the bed features but does not influence the wave length of the feature.

A phenomenon that is not included in this model is the influence the shape of the North Sea basin may have on the occurrence of sand banks. This is investigated by Carbajal et al. (2005), and they show that the geometry of the basin may play a role in sand bank formation and in combination with the incident Kelvin wave may favor the generation of sand banks. Their model calculations for the southern North Sea basin agree with observations of sand banks in this area.

The prediction of a flat bed while sand banks are occurring does not necessarily have to be an incorrect prediction. The banks observed can be formed during periods of lower sea level (moribund sand banks) or can be relict features; in these cases, based on the current flow conditions, no sand banks are predicted. Unfortunately, the authors did not find such information on the origin of tidal sand banks in the North Sea in the scientific literature. Therefore, at this point, it is impossible to determine which sand banks are actively maintained by the nowadays conditions, which are moribund and which are relict features.

As several large-scale patterns occur simultaneously in the North Sea (Knaapen et al. 2001), detailed analysis of the seabed is required to detect sand banks. Therefore, if amplitudes are relatively small, it may be difficult to recognize them, explaining why they do not occur yet on maps. The model predicts sand bank occurrence in a large part of the southern North Sea. This coincides with Knaapen (2009) who finds that many more sand banks exist on the (Dutch part of the) North Sea seabed than are reported in literature. Here, we based our knowledge on the occurrence of sand banks on other sources, and to avoid discussions on definitions and the origin of sand banks, we have chosen not to change them.

Especially, the value of the level of zero intercept $\left(z_{0}\right)$ has a large influence on the predictions. In this chapter, we use a predictor of the value of $z_{0}$ based on the dimensionless average parameters of megaripples for a North Sea environment. The prediction of the value of $z_{0}$ may improve if another predictor for its value is used. Therefore, further research on an accurate prediction method for this parameter may lead to values of $z_{0}$ that may increase the quality of the predictions.

\section{Conclusion}

Without any tuning or calibration, the occurrence of sand banks in the North Sea is predicted correctly in $64.5 \%$ of the area. Therefore, when developing a human activity in the North Sea area (like sand mining, pipelines, or wind farms), it is important to do a detailed survey of the area and to take into account the effect of the activity of the dynamics of the seabed and vice versa.

However, the area in which sand banks are predicted is too large. Apparently, there is room for further improvement, and other physical processes predicting the occurrence of sand banks in the North Sea might be added in the model or, alternatively, the occurrence of sand banks with small amplitudes is still underestimated. 
The sensitivity analysis shows that the influence of the level of zero intercept $\left(z_{0}\right)$ in the turbulence model is important for the quality of the predictions. The optimal prediction is made when we use a variable value of $z_{0}$ based on dimensionless coefficients for the megaripple regime (Eq. 6) with values of $z_{0}$ that are very close to the original values that are used in the model $\left(2.3 \times 10^{-2}\right.$ and $\left.6.4 \times 10^{-} \mathrm{m}\right)$. When we take $80 \%$ of the variable values of $z_{0}$, this gives the most optimal results (a correct prediction in $64.8 \%$ of the area).

Open Access This article is distributed under the terms of the Creative Commons Attribution Noncommercial License which permits any noncommercial use, distribution, and reproduction in any medium, provided the original author(s) and source are credited.

\section{References}

Boon JG, Gerritsen H (1997) Modelling of suspended particulate matter (SPM) in the North Sea: a dedicated orthogonal boundaryfitted modelling approach (PROMISE), Delft Hydraulics, Delft, The Netherlands.: Res.Rep. Z2025

Brown E, Colling A, Park D, Phillips J, Rothery D, Wright J (1999) Waves, tides and shallow-water processes. The Open University, Oxford

Carbajal N, Piney S, Rivera JG (2005) A numerical study on the influence of geometry on the formation of sandbanks. Ocean Dynamics 55:559-568. doi:10.1007/s10236-005-0034-1

Collins MB, Shimwell SJ, Gao S, Powell H, Hewitson C, Taylor JA (1995) Water and sediment movement in the vicinity of linear sandbanks: the Norfolk Banks, southern North Sea. Mar Geol $123: 125-142$

Davies AM, Kwong SCM, Flather RA (1997) Formulation of a variable-function three-dimensional model, with application to the M2 and M4 tide on the North-West European continental shelf. Cont Shelf Res 17:165-204

Dyer KR, Huntley DA (1999) The origin, classification and modeling of sand banks and ridges. Cont Shelf Res 19:1285-1330

Hulscher SJMH (1996) Tidal-induced large-scale regular bed form patterns in a three-dimensional shallow water model. J Geophys Res 101(C9):20,727-20,744

Hulscher SJMH, Roelvink JA (1997) Comparison between predicted and observed large-scale sea bed features in the southern North Sea. Research report. University of Twente, Enschede, The Netherlands

Hulscher SJMH, Van den Brink GM (2001) Comparison between predicted and observed sand waves and sand banks in the North Sea. J Geophys Res 106(C5):9327-9338

Hulscher SJMH, De Swart HE, De Vriend HJ (1993) The generation of offshore tidal sand banks and sand waves. Cont Shelf Res 101 (C9):1183-1204
Hydrographer_of_the_Navy (1992). Spurn, East Anglia: Associated British ports; Thames estuary, Taunton, Engl., U.K.

Hydrographical_Survey (2000) Tidal heights and streams, coastal waters of the Netherlands and adjacent areas. Royal Dutch Navy, Hydrographical Survey, HP33, p.308

Idier D, Van der Veen HH, Hulscher SJMH (2007). Influence of grain size on sandbanks dynamics. Proceedings of the 5th IAHR symposium on River, Coastal and Estuarine Morphodynamics (RCEM2007), Enschede, The Netherlands

Jarke J (1956) Der Boden der Südlichen Nordsee. Deutsche Hydrografische Zeitschrift 9:1-9

Knaapen MAF (2009) Sandbank occurrence on the Dutch continental shelf in the North Sea. Geo-Mar Lett 29:17-24. doi:10.1007/ s00367-008-0105-7

Knaapen MAF, Hulscher SJMH, Stolk A, De Vriend HJ (2001) A new type of sea bed waves. Geophys Res Lett 28(7):1323-1326

Prandle D (1982) The vertical structure of tidal currents. Geophys Astrophys Fluid Dyn 22:29-48

Rijks_Geologische_Dienst (1984). Geological charts of the North Sea: indefatigable, Flemish bight, Ostend, Haarlem, The Netherlands

Roos PC, Hulscher SJMH, Knaapen MAF, Van Damme RMJ (2004) The cross-scectional shape of tidal sand banks. Modelling and observations. J Geophys Res 109(F2):F02003. doi:10.1029/ 2003JF000070

Soulsby RL (1983) The bottom boundary layer of shelf seas. Physical oceanography of coastal and shelf seas. Elsevier, Amsterdam, pp $189-266$

Soulsby RL (1990) Tidal-current boundary layers. In: le Mehaute B, Hanes DM (eds) The sea, vol. G, part A. Ocean Engineering Science, Wiley, New York, pp 523-566

Soulsby RL (1997) Dynamics of marine sands: a manual for practical applications. Thomas Telford, London

Soulsby RL, Whitehouse RJSW (1997) Treshold of sediment motion in coastal environments. Proc. Pacific Coasts and Ports, Christchurch. University of Canterbury, New Zealand

Ten Brummelhuis PGJ, Gerritsen H, Van der Kaay T (1997) Sensitivity analysis and calibration of the orthogonal boundaryfitted coordinate model PROMISE for tidal flow: the use of adjoint modelling techniques, Delft Hydraulics, Delft, The Netherlands: Res. Rep. Z2025

Tobias CJ (1989) Morphology of sand waves in relation to current, sediment and wave data along the Eurogeul, North Sea, Dep. of Phys. Geogr., Univers. of Utrecht, Utrecht, The Netherlands: Rep. Geopro 1989.01

Van der Molen J (2002) The influence of tides, wind and waves on the net sand transport in the North Sea. Cont Shelf Res 22:27392762

Van der Veen HH, Hulscher SJMH, Knaapen MAF (2006) Grain size dependency in the occurrence of sand waves. Ocean Dynamics 56:228-234. doi:10.1007/s10236-005-0049-7

Van Dijk R, Plieger R (1988) Definitieve versie ZUNOWAK model (in Dutch), Rijkswaterstaat, Dienst Getijdewateren, The Hague, The Netherlands: GWAO-88.381

Van Rijn LC (1993) Principles of sediment transport in rivers, estuaries and coastal seas. Aqua, Amsterdam 